\title{
Extraction of natural dye from the leaves of Wild Himalayan pear (Pyruspashia) and optimization of the dyeing parameters using Box-Behnken Design (RSM)
}

\author{
Manisha Kumari \\ Department of Clothing and Textiles, College of Home Science, Govind Ballabh Pant \\ University of Agriculture and Technology, Pantnagar, U.S. Nagar-263145 (Uttarakhand), India \\ Manisha Gahlot \\ Department of Clothing and Textiles, College of Home Science, Govind Ballabh Pant \\ University of Agriculture and Technology, Pantnagar, U.S. Nagar-263145 (Uttarakhand), India \\ Anita Rani \\ Department of Clothing and Textiles, College of Home Science, Govind Ballabh Pant \\ University of Agriculture and Technology, Pantnagar, U.S. Nagar-263145 (Uttarakhand), India \\ Sakshi \\ Department of Clothing and Textiles, College of Home Science, Govind Ballabh Pant \\ University of Agriculture and Technology, Pantnagar, U.S. Nagar-263145 (Uttarakhand), India \\ ${ }^{*}$ Corresponding author. E. mail: manisha52729@gmail.com
}

\section{Article Info}

https://doi.org/10.31018/

jans.v12i4.2383

Received: October 1, 2020

Revised: November 7, 2020

Accepted: November 12, 2020

\section{How to Cite}

Kumari, M. et al. (2020). Extraction of natural dye from the leaves of Wild Himalayan pear (Pyruspashia) and optimization of the dyeing parameters using Box-Behnken Design (RSM). Journal of Applied and Natural Science, 12(4): 497- 503. https:// doi.org/10.31018/jans.v12i4.2383

\begin{abstract}
Today universe is inclined towards eco-friendly and sustainable products. Its interest is shifting from synthetic products to natural once. The present study involves the optimization of extraction $\mathrm{pH}$ of natural dye and optimization of dyeing parameters for dyeing of silk fabric using response surface methodology (RSM). The extraction of dye from the leaves of Pyrus pashia (Wild Himalayan pear) was carried out in acidic, neutral and alkaline $\mathrm{pH}$. The neutral $\mathrm{pH}$ exhibited the highest colour strength than alkaline and acidic $\mathrm{pH}$. Box-Behnken Design (RSM) was used for optimization of dyeing variables. The effect of independent variables i.e. dye material concentration, dyeing time and temperature were assessed on dependent variable i.e colour strength of the dyed silk fabric sample. The optimized dyeing variables obtained for application of $P$. pashia leaf dye on silk fabric were $5 \%(\mathrm{w} / \mathrm{v})$ dye material concentration, $70^{\circ} \mathrm{C}$ dyeing temperature and 45 minutes dyeing time. It not only creates a source for a natural dye but can also lead to creating employment amongst the rural people. $P$. pashia has a potential to colour silk fabric and can be used to dye other natural fibres such as cotton and wool which can be a step towards sustainable development. dyeing with its leaf extract can be helpful in promoting eco-friendly processing of textiles.
\end{abstract}

Keywords: Box-Behnken Design, Eco-friendly dye, Pyrus pashia, Silk dyeing

\section{INTRODUCTION}

The dyes which are extracted from different parts of plants such as a leaf, seed, bark, fruit and flower that contain colouring materials like tannin, flavonoids, quinonoid, etc. are called natural dyes. The environmental compatibility and quality of the natural dyestuff make them more popular among the consumers (Kasiri and Safapour, 2015). Synthetic dyes can be replaced with natural dyes if they have the potential to exhibit similar fastness characteristics to the synthetic once. Natural dyes can be used as a safer alternative to where health and safety demands are greater, e.g. baby clothes with pale shades. These dyes are not only used in the production of high added-value eco-friendly textile products but can also be used in various other categories like food, cosmetics industries and packaging for the production of novel ecofriendly materials (Savvidis et al., 2014).

Consumers are becoming more aware of environmental and health issues. Sustainability is being promoted in all aspects of colouration, and zero-discharge processing is becoming very popular.

The use of natural dyes reduces pollution problems. In some cases, the waste obtained in the process becomes an ideal fertilizer for agricultural fields. According to a study that effluent produced by different natural dyes have a BOD value of $40-85 \mathrm{mg} / \mathrm{L}$ which was less than the limit of $100 \mathrm{mg} / \mathrm{L}$ prescribed by the Central Pollution Control Board (CPCB), Government of 
India (Henriques and Shankar, 2007). Natural dyeing practices are helpful in promoting rural entrepreneurship by creating employment opportunities in rural areas. Focusing on such sources, which are not useful or economical and can be used to produce colour on the textile substrate without causing any harm to the environment would be a good initiative (Samanta, 2020). Pyrus pashia is one of such natural resources which is not economically beneficial and can be used to produce dye. Thus, with a view to further explore a new plant source of natural dye, the present research was carried out for extraction of the dye and optimization of dyeing parameters for dyeing of silk fabric from the leaves of $P$. pashia.

\section{MATERIALS AND METHODS}

\section{Dye source (leaves of Pyrus pashia)}

Botanical name: Pyrus pashia Buch.-Ham. exD. Don

Family: Rosaceae

Genus: Pyrus

Species : Pyrus pashia

English name: Wild himalayan pear, Indian wild pear Hindi name: Kainth, Kainath, Mole, Mehal

Part used: Leaves

$P$. pashia is also known as wild Himalayan pear and is native to southern Asia. It is a small to medium-sized deciduous tree. The tree has finely toothed leaves, attractive white flowers with red anthers and small pear -like fruits. This is described as an intermediate species between oriental and occidental pear groups. It is one of the most important wild pears and has played an important role in the evolution of the Pyrus genus and it is widely used as a pear rootstock in Southwest China (Zong et al., 2013). The leaves of $P$. pashia are also rich in phenolic compounds which are responsible for its antioxidant property (Tsering et al., 2012).

Optimization of the extraction process: The plant leaves were collected, washed thoroughly with running tap water and dried in the shade for 10-12 days. Finally, the leaves were dried in a hot air oven at $50^{\circ} \mathrm{C}$ for half an hour and ground into a fine powder using an electric grinder. Dye powder was extracted in the water at three different $\mathrm{pH}$, namely alkaline (9), acidic (6) and neutral (7).

One gram of sodium carbonate and $1 \mathrm{ml}$ of acetic acid were added in two beakers containing $100 \mathrm{ml}$ of distilled water for alkaline and acidic medium respectively. Two-gram dye powder mass was added to each beak$\mathrm{er}$, and the dye was extracted at $80^{\circ} \mathrm{C}$ for 1 hour. The solutions were filtered, $\mathrm{pH}$ of the filtered extracts were measured, and it was made neutral by adding $1 \mathrm{ml}$ acetic acid and $0.10-0.12 \mathrm{~g}$ of sodium carbonate in alkaline and acidic extract respectively. For neutral $\mathrm{pH}$, $2 \mathrm{~g}$ dye powder mass was extracted in $100 \mathrm{ml}$ distilled water. Extraction was done at $80^{\circ} \mathrm{C}$ for 1 hour. The extract was filtered, and $\mathrm{pH}$ of the dye was found neutral. Three extracts were used to dye presoaked silk fabric samples at $80^{\circ} \mathrm{C}$ for the duration of 1 hour in
HTHP (High-Temperature High Pressure) beaker dyeing machine. After dyeing the samples were removed from the dyeing machine, allowed to cool and rinsed under running tap water. Samples were dried in shade and their colour strength was assessed by using Spectrophotometer. The extraction $\mathrm{pH}$ that yielded highest colour strength was selected for further study.

Optimization of dyeing parameters: In this study, the optimization of dyeing independent variables, i.e. dye concentration, dyeing time and dyeing temperature was carried out. For optimization of dye concentration, different quantities of $P$. pashia dye material (3, $4,5,6$ and $7 \mathrm{~g} / 100 \mathrm{ml}$ ) were taken in 5 beakers separately, and extraction was carried out at selected extraction $\mathrm{pH}$ for 1 hour at $80^{\circ} \mathrm{C}$. In case of dyeing temperature and dyeing time, dyeing was carried out for 1 hour at four different temperatures $\left(60,70,80\right.$ and $90^{\circ}$ C) and durations (45, 60, 75 and 90 minutes) in separate beakers. Dyeing was carried out in HTHP beaker dyeing machine. Thereafter colour strength was assessed to establish the optimum dye temperature and dyeing time for determining the upper limit and lower limit.

Dye concentration, dyeing time and dyeing temperature were taken as independent variables in the present study. The effect of these independent variables was studied later on the colour property of $P$. pashia dyed silk fabric samples, i.e. colour strength. The levels of experiments, along with coded values investigated in this research, are given in Table 1. The colour strength was taken as a dependent variable or response of the system.

Three factors with their low and high level are given in Table 1 . The design provided a total of 17 experiments, out of which 5 experiments were with the centre level values $(0,0$, and 0$)$ mentioned in Table 2 . Regression and graphical analysis of data was obtained by using Design Expert Version 10. The optimized values of the independent variables were obtained with the analysis of the response surface 3D graph and by solving the regression equation. The variability in the response, i.e. dependent variables, was interpreted with the help of R-square value i.e. coefficient of determination. The model equation was used to predict the optimum values and explain the interaction between the factors within the specified range.

\section{RESULTS AND DISCUSSION}

Optimized extraction process: Colour strength of silk fabric samples dyed with dye extracted at three different $\mathrm{pH}$ (alkaline, acidic and neutral) are given in Table 3. It is evident from the table that silk fabric samples dyed with extract of neutral $\mathrm{pH}$ showed the highest colour strength value (5.736) followed by acidic $\mathrm{pH}$ (4.43) and alkaline $\mathrm{pH}$ (3.772). Hence, neutral $\mathrm{pH}$ was selected for further study. According to Yusuf (2018) prolonged action of acid and alkali cause hydrolysis of peptide bonds which leads to degradation of silk poly- 
Table 1. Variables for $P$. pashia leaf dye with their coded and actual levels for dyeing of silk fabric.

\begin{tabular}{lcccc}
\hline \multicolumn{1}{c}{ Factors } & \multirow{2}{*}{ Code } & \multicolumn{3}{c}{ Levels } \\
\cline { 3 - 5 } & & $\mathbf{- 1}$ & $\mathbf{0}$ & $\mathbf{+ 1}$ \\
\hline Dye concentration $(\mathrm{g} / 100 \mathrm{ml})$ & $\mathrm{A}$ & 3 & 5 & 7 \\
Dyeing time $($ minutes) & $\mathrm{B}$ & 45 & 60 & 75 \\
Dyeing temperature $\left({ }^{\circ} \mathrm{C}\right)$ & $\mathrm{C}$ & 70 & 80 & 90 \\
\hline
\end{tabular}

Table 2. Design matrix for $P$. pashia leaf dye according to Box Behnken design with levels in coded and actual form.

\begin{tabular}{|c|c|c|c|c|c|c|}
\hline \multirow[t]{3}{*}{ Run } & \multirow{2}{*}{\multicolumn{3}{|c|}{ Coded values }} & \multicolumn{3}{|c|}{ Independent variables } \\
\hline & & & & \multicolumn{3}{|c|}{ Actual values } \\
\hline & A & B & C & $\begin{array}{c}\text { Dye conc. } \\
(\% w / v)\end{array}$ & $\begin{array}{l}\text { Dyeing Time } \\
\text { (Min) }\end{array}$ & $\begin{array}{c}\text { Dyeing Temp. } \\
\left({ }^{\circ} \mathrm{C}\right)\end{array}$ \\
\hline 1 & 1 & 0 & 1 & 7 & 60 & 90 \\
\hline 2 & 1 & 0 & -1 & 7 & 60 & 70 \\
\hline 3 & 1 & 1 & 0 & 7 & 75 & 80 \\
\hline 4 & -1 & 0 & 1 & 3 & 60 & 90 \\
\hline 5 & -1 & -1 & 0 & 3 & 45 & 80 \\
\hline 6 & 0 & 0 & 0 & 5 & 60 & 80 \\
\hline 7 & -1 & 0 & -1 & 3 & 60 & 70 \\
\hline 8 & 0 & -1 & -1 & 5 & 45 & 70 \\
\hline 9 & 0 & 0 & 0 & 5 & 60 & 80 \\
\hline 10 & 0 & 0 & 0 & 5 & 60 & 80 \\
\hline 11 & 0 & 1 & -1 & 5 & 75 & 70 \\
\hline 12 & 0 & 1 & 1 & 5 & 75 & 90 \\
\hline 13 & 0 & 0 & 0 & 5 & 60 & 80 \\
\hline 14 & 0 & 0 & 0 & 5 & 60 & 80 \\
\hline 15 & 1 & -1 & 0 & 7 & 45 & 80 \\
\hline 16 & 0 & -1 & 1 & 5 & 45 & 90 \\
\hline 17 & -1 & 1 & 0 & 3 & 75 & 80 \\
\hline
\end{tabular}

mer and complete destruction of silk polymer. Researchers like Jothi (2008) and Punrattanasin et al. (2013) had extracted dye from natural sources in aqueous medium at neutral $\mathrm{pH}$ for dyeing of silk fabric.

\section{Optimized dyeing parameters}

Concentration of dye material: Colour strength of silk fabric samples dyed with $P$. pashia leaves at different dye material concentration are given in Table 4, and highest colour strength (6.771) was obtained when dyeing was carried out with $5 \mathrm{~g}$ dye concentration. Taking into consideration the colour strength values, $5 \mathrm{~g}$ was selected as mid-value, $3 \mathrm{~g}$ was selected as the lower limit and $7 \mathrm{~g}$ was selected as the upper limit for further optimization using Response Surface Methodology. Guesmi et al. (2012) stated that the colour strength value increased as the dye material concentration increased up to a certain level after which the fibre started to become saturated. Shabbir et al., (2017) also reported that an increase in colour strength $(K / S)$ was observed with the increase in the dye concentration, resulting in deeper shades. It was also mentioned in the study that increases in dye concentration in the dye bath, concentration gradient in- creased, which resulted in an increase in the rate of diffusion of dye onto the surface of yarn from the dyebath solution.

Dyeing temperature: Table 5 shows the colour strength values of silk fabric samples dyed with $P$. pashia leaves dye at different temperatures, i.e. 60 , 70,80 and $90^{\circ} \mathrm{C}$. With the increase in dyeing temperature, the colour strength value of the dyed silk also increased from $60^{\circ} \mathrm{C}$ to $90^{\circ} \mathrm{C}$. on the basis of colour strength, $80^{\circ} \mathrm{C}$ was selected as mid value, $70^{\circ} \mathrm{C}$ was selected as the lower limit and $90^{\circ} \mathrm{C}$ was selected as the upper limit for further optimization using Response Surface methodology.

The above statement can be justified with the study of Samanta et al. (2011). They evaluated the effect of different dyeing process variables on colour strength on jute fabric dyed with tesu extract. They found that on increasing the dyeing temperature $\left(60-100^{\circ} \mathrm{C}\right)$ the colour strength increased miserably from $60-90^{\circ} \mathrm{C}$ and then dropped down. An increase in dyeing temperature supplied more energy to dye molecule to penetrate in the fiber polymer system thus facilitating the higher rate of dye absorption and diffusion up to $90^{\circ} \mathrm{C}$ 
Table 3. Colour strength of silk fabric samples dyed with dye extracted at different $\mathrm{pH}$.

\begin{tabular}{lll}
\hline S.No. & Extraction pH & K/S \\
\hline 1 & Acidic (6) $^{*}$ & 4.430 \\
2 & Neutral $^{*}(7)$ & 5.736 \\
3 & Alkaline (9) & 3.772 \\
\hline
\end{tabular}

*selected $\mathrm{pH}$

Table 4. Colour strength of silk fabric samples dyed with $P$. pashia leaves at different dye material concentration.

\begin{tabular}{lll}
\hline S.No. & $\begin{array}{l}\text { Dye material concentration } \\
\text { (g/100ml) }\end{array}$ & $\mathrm{K} / \mathrm{S}$ \\
\hline 1 & 3 & 6.625 \\
2 & 4 & 5.931 \\
3 & $5^{\star}$ & 6.771 \\
4 & 6 & 6.620 \\
5 & 7 & 6.849 \\
\hline
\end{tabular}

*Selected dye material concentration for further experiments

Table 5. Colour strength of silk fabric samples dyed with $P$. pashia leaves dye at different dyeing temperature.

\begin{tabular}{lll}
\hline S.No. & Dyeing temperature $\left({ }^{\circ} \mathbf{C}\right)$ & K/S \\
\hline 1 & 60 & 5.630 \\
2 & 70 & 6.849 \\
3 & $80^{*}$ & 6.855 \\
4 & 90 & 6.867 \\
\hline
\end{tabular}

*Selected dyeing temperature for further experiments

Table 6. Colour strength of silk fabric samples dyed with $P$. pashia leaves dye for different durations.

\begin{tabular}{lll}
\hline S.No. & Dyeing time (minutes) & K/S \\
\hline 1 & 45 & 6.291 \\
2 & 60 & 6.553 \\
3 & 75 & 6.770 \\
4 & 90 & 6.198 \\
\hline
\end{tabular}

before the desorption starts at relatively higher temperature $100^{\circ} \mathrm{C}$. Raza et al., (2018) also reported the same results in their study. They found $70{ }^{\circ} \mathrm{C}$ temperature as optimal dyeing temperature for dyeing of irradiated viscose using irradiated munj sweet cane inflorescence extract and a further increase in dyeing temperature caused a decline in colour strength of viscose. According to Shenai (1997), upon increasing the dyeing temperature, the fibre polymer system swells, and disaggregation of dye takes place, which enhances the diffusion of dye into the fibre polymer system. It was also reported by Farooq et al. (2013) that the colour strength values of the cotton dyed samples increased with an increase in dyeing temperature.

Dyeing time: Table 6 shows the colour strength values of silk fabric samples dyed with $P$. pashia leaf dye at an optimized temperature $\left(80^{\circ} \mathrm{C}\right)$ for different durations from 45 to 90 minutes. As evident from the table 4.6, colour strength of dyed samples improved up to a certain limit and then dropdown. Design-Expert Software, 60 minutes dyeing was taken as mid-value, 45 minutes taken as the lower limit and 75 minutes taken as the upper limit. According to Mongkholrattanasit (2011), dyeing for a longer time helped in increasing the colour strength values until the dye exhaustion attained equilibrium. It was also reported by Raza et al. (2018) that more the dyeing time more will be the colour strength. With the increase in dyeing time, the dye molecules rushed onto the fabric continuously until it reached its maximum.

Optimized dyeing process: Table 7 shows the data resulting from the experiments of the effect of three variables of dyeing, i.e. dye concentration, dyeing time and dyeing temperature on the colour strength of the silk dyed sample. It is clear from the table that the colour strength of dyed silk fabric samples ranged from 5.567 to 7.15 . The maximum colour strength (7.15) was obtained when dyeing was carried out using $7 \%$ dye at $70^{\circ} \mathrm{C}$ for the duration of 60 minutes, whereas the minimum colour strength (5.567) was attained when dyeing was carried out using $5 \%$ dye at $90^{\circ} \mathrm{C}$ for the duration of 45 minutes.

The quadratic model was used to describe the mathematical relationship between the independent variables and dependent variables. The mathematical expression of relationship to the colour strength with variables such as $A, B$ and $C$ are given below in terms of coded factors

$\mathrm{K} / \mathrm{S}=6.91+0.25^{*} \mathrm{~A}+0.21^{*} \mathrm{~B}-0.19 \mathrm{C}+0.24 \mathrm{AB}-0.33^{*} \mathrm{AC}$ $+0.060 B C-0.41^{*} A^{2}-0.48^{*} B^{2}-0.39^{*} C^{2}$

and in terms of actual factors-

$\mathrm{K} / \mathrm{S}=-30.67098+1.98869^{*}$ dye conc $+0.19539^{*}$ time $+0.66960^{*}$ temp $+7.95833 \mathrm{E}-003^{*}$ dye conc* time $0.016562{ }^{*}$ dye conc * temp $+3.98333 \mathrm{E}-004^{*}$ time * temp

The significance of the effect of dyeing variables on the colour strength of dyed silk fabric samples was assessed with the help of analysis of variance. It was clear from Table 8 that the model was significant as the p-value $(0.0140)$ of the model was less than 0.05 , i.e. model was significant at $1 \%$ level of significance. The coefficient of determination $\left(R^{2}\right)$ for the regression model of colour strength was 0.8847 , and depicted variability in the colour strength of dyed fabric samples was 88.47 which was due to the combined effect of all dyeing variables at linear and quadratic levels. The value of $R^{2}$ shows the highest correlation between the predicted and observed values when it was near 1 . Adequate precision measures the signal to noise ratio (SNR), and the model's adequate precision greater than 4 (adeq. precision $>4$ ) is desirable. The value of adequate precision of the model was 6.044 .

Fig. 1 shows the combined effect of dye concentration 
Table 7. Dyeing conditions and observed response for silk fabric samples dyed with Pyrus pashia leaf dye.

\begin{tabular}{|c|c|c|c|c|c|}
\hline \multirow[b]{2}{*}{ Std. } & \multirow[b]{2}{*}{ Run } & \multicolumn{3}{|c|}{ Independent variables } & \multirow{2}{*}{$\begin{array}{l}\text { Dependent variable } \\
\text { Colour strength } \\
(\mathrm{k} / \mathrm{s})\end{array}$} \\
\hline & & $\begin{array}{l}\text { Factor A: Dye } \\
\text { concentration (\% w/v) }\end{array}$ & $\begin{array}{l}\text { Factor B: Dyeing } \\
\text { time (minutes) }\end{array}$ & $\begin{array}{l}\text { Factor C: Dyeing temp. } \\
\left({ }^{\circ} \mathrm{C}\right)\end{array}$ & \\
\hline 10 & 1 & 5 & 75 & 70 & 6.406 \\
\hline 15 & 2 & 5 & 60 & 80 & 7.062 \\
\hline 9 & 3 & 5 & 45 & 70 & 5.875 \\
\hline 2 & 4 & 7 & 45 & 80 & 5.795 \\
\hline 16 & 5 & 5 & 60 & 80 & 7.062 \\
\hline 11 & 6 & 5 & 45 & 90 & $5.567^{\star}$ \\
\hline 12 & 7 & 5 & 75 & 90 & 6.337 \\
\hline 13 & 8 & 5 & 60 & 80 & 6.589 \\
\hline 5 & 9 & 3 & 60 & 70 & 5.650 \\
\hline 4 & 10 & 7 & 75 & 80 & 6.444 \\
\hline 17 & 11 & 5 & 60 & 80 & 7.006 \\
\hline 6 & 12 & 7 & 60 & 70 & $7.15^{\star \star}$ \\
\hline 14 & 13 & 5 & 60 & 80 & 6.855 \\
\hline 8 & 14 & 7 & 60 & 90 & 5.918 \\
\hline 3 & 15 & 3 & 75 & 80 & 5.795 \\
\hline 1 & 16 & 3 & 45 & 80 & 6.101 \\
\hline 7 & 17 & 3 & 60 & 90 & 5.743 \\
\hline
\end{tabular}

*lowest value and **highest value

Table 8. ANOVA results for the quadratic equation for colour strength.

\begin{tabular}{llllll}
\hline Source & $\begin{array}{l}\text { Sum of } \\
\text { squares }\end{array}$ & $\begin{array}{l}\text { Degree of } \\
\text { freedom }\end{array}$ & Mean square & F-value & $\boldsymbol{P}$ \\
\hline Model & 4.38 & 9 & 0.49 & 5.97 & 0.0140 \\
Residual & 0.57 & 7 & 0.081 & & \\
Lack of fit & 0.41 & 3 & 0.14 & 3.38 & 0.1350 not significant \\
Pure error & 0.16 & 16 & 0.040 & & \\
Total & 4.95 & 16 & & & \\
\hline
\end{tabular}

$R^{2}$ : 0.8847; AdjR²: 0.7366; Std. dev: 0.29; Adeq Precision: 6.044

$(\mathrm{A})$ and dyeing time $(\mathrm{B})$ keeping the dyeing temperature $(\mathrm{C})$ optimum $\left(80^{\circ} \mathrm{C}\right)$ on colour strength of dyed silk fabric samples. It was clear from the figure that colour strength increased as dye concentration was increased from low to mid level but further decreased on increasing dye concentration from mid to upper level. The colour strength also increased as the dyeing time was increased from low to mid level but further decreased on increasing the dyeing time from mid to upper level. Both the factors dye concentration $(A)$ and dyeing time $(B)$ positively influenced the colour strength of the dyed silk fabric samples up to the mid level and afterwards behaved negatively for colour strength.

Fig. 2 depicts the effect of dye concentration (A) and dyeing temperature $(C)$ on colour strength of dyed silk fabric samples keeping the third factor i.e. dyeing time (B) at optimum level (60 minutes). It was clear from the figure that colour strength increased from 5.75 to 6.93 with the increase in dye concentration from lower to upper limit whereas in case of increase in dyeing temperature from lower to mid level the colour strength increased but further decreased on increasing dyeing temperature from mid to upper limit. The effect of dyeing concentration was more prominent than the effect of dyeing temperature. The maximum colour strength value (6.93) was obtained at $7 \%$ dye concentration and $70^{\circ} \mathrm{C}$ temperature whereas lowest colour strength value (5.75) was obtained at $3 \%$ dye concentration and $70^{\circ} \mathrm{C}$ temperature.

Fig. 3 shows the interactive effect of dyeing time (B) and dyeing temperature $(C)$ keeping the dye concentration (A) at optimum level $5 \%$. The colour strength increased as the dyeing time increased to mid level but decreased with the further increase in dyeing time from mid to upper level. The colour strength showed increase initially but further decreased on increasing dyeing temperature. The maximum colour strength value (6.66) was obtained when dyeing was carried out at about $80^{\circ} \mathrm{C}$ temperature for 60 minutes whereas 


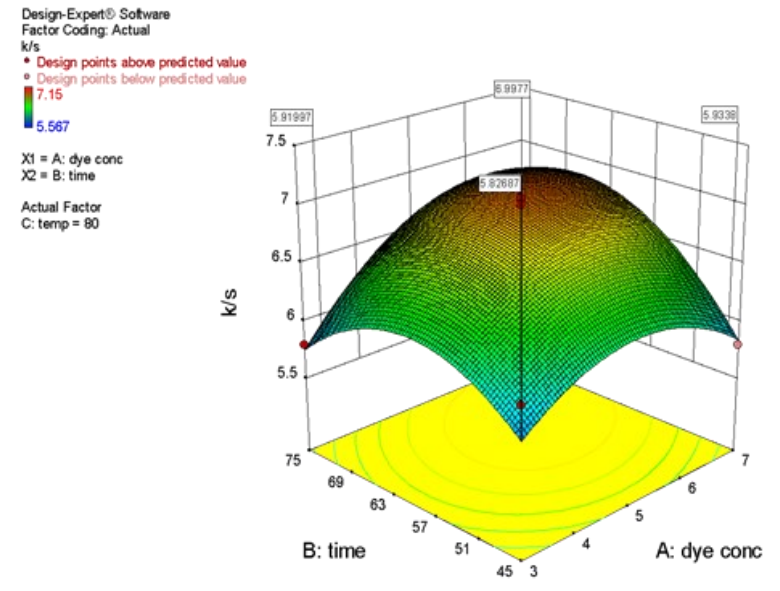

Fig. 1. Interactive effect of dye concentration (A) and dyeing time $(B)$ on the colour strength of dyed silk fabric samples.

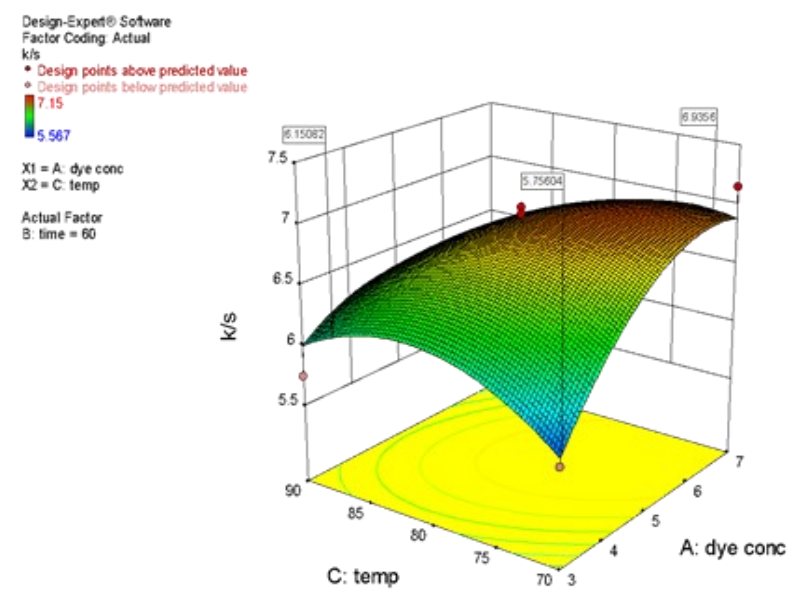

Fig. 2. Interactive effect of dye concentration (A) and dyeing temperature $(C)$ on the colour strength of the dyed silk fabric sample.

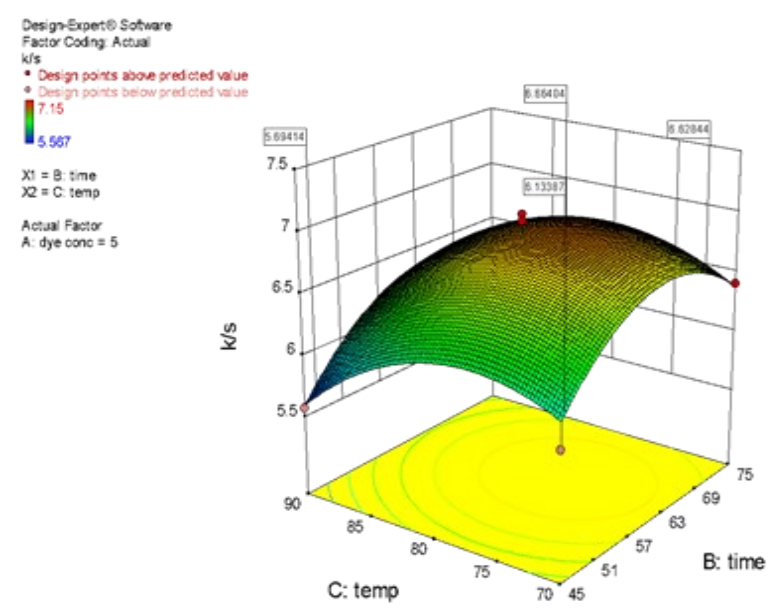

Fig. 3. Interactive effect of dyeing time (B) and dyeing temperature (C) on the colour strength of the dyed silk fabric sample. the lowest value of colour strength (5.69) was obtained at $90^{\circ} \mathrm{C}$ temperature and 45 minutes dyeing time.

Validation of model: The verification of the model was done by comparing the experimental value with the predicted value given by the software. The experimental value for colour strength was close to the predicted theoretical value. An average experimental value, 5.875, was obtained against predicted value 6.090 for colour strength. Only a slight difference was found between the predicted and experimental value for the dyeing of silk fabric. It can be concluded that the precision and appropriateness of the optimized conditions as well as the applied mathematical models, was sufficient. Therefore, the optimized value of dye material concentration, dyeing time and temperature predicted by the numerical optimization was selected for dyeing of silk fabric.

\section{Conclusion}

Analysis of Box-Behnken Design for optimization of dyeing variables revealed that the linear and quadratic effect of dye concentration, dyeing time and temperature on colour strength of silk fabric samples was significant at $5 \%$ level of significance whereas the interactive effect of all three factors was non-significant. Variability in the colour strength of dyed silk fabric samples was $88.47 \%$ due to the combined effect of all dyeing variables at linear and quadratic levels. The optimized recipe given by BBD for dyeing of silk fabric with $P$. pashia leaf extract was $5 \%$ dye material concentration, 45 minutes dyeing time and $70^{\circ} \mathrm{C}$ dyeing temperature. The leaf dye was found to give maximum colour strength when the dye was extracted at neutral $\mathrm{pH}$. The leaf extract can be used to produce colour on silk fabric. It is a novel and renewable source of dye for dyeing of silk fabric. Dyeing with $P$ pashia leaf extract can be helpful in promoting eco-friendly processing of textiles.

\section{Conflict of interest}

The authors declare that they have no conflict of interest.

\section{REFERENCES}

1. Farooq, A., Ali, S., Abbas, N., Zahoor, N., \& Ashraf, M. A. (2013). Optimization of extraction and dyeing parameters for natural dyeing of cotton fabric using Marigold (Tagetes erecta). Asian Journal of Chemistry, 25(11), 5955-5959. doi:10.14233/ajchem.2013.14202

2. Guesmi, A., Hamadi, N. B., Ladhari, N. and Sakli, F. (2012). Dyeing properties and colour fastness of wool dyed with indicaxanthin natural dye. Industrial Crops and Products, 37(1), 493-499. doi:10.1016/j.indcrop.2011.0 7.026

3. Henriques, B. M. A. and Shankar, A. (2007).Natural dyeing for pollution free colouration of textiles by rural artisans and for revegetation of cultivable wastelands. Paper presented in stakeholders' workshop, ICEF Project on promotion of natural dyes in textile industries for environ- 
mental improvement and sustainable livelihood, Mumbai

4. Jothi, D. (2008). Extraction of Natural Dyes from African Marigold Flower (Tagetesereecta $L$ ) for Textile Coloration. AUTEX Research Journal, 8(2):49-53.

5. Kasiri, M.B. and Safapour S. 2015. Exploring and exploiting plants extracts as the natural dyes/antimicrobials in textiles processing (review paper). Progress in color, colorants and coatings , 8(2)

6. Mongkholrattanasit, R., Kryštůfek, J., Wiener, J. and Vikova, M. 2011. UV protection properties of silk fabric dyed with eucalyptus leaf extract. Journal of the Textile Institute, 102(3): 272-279.

7. Punrattanasin, N., Nakpathom, M., Somboon, B., Narumol, N., Rungruangkitkrai, N. and Mongkholrattanasit, R. (2013). Silk fabric dyeing with natural dye from mangrove bark (RhizophoraapiculataBlume) extract. Industrial Crops and Products, 49: 122-129.

8. Raza, A., lqbal, N., Mahmood, S., Parveen, S., Azeem, M., Nawaz, M. and Noman, A. (2018). Harnessing natural colorants for sustainable textile dyeing an eco -friendly approach using sweet cane (Saccharum Bengalense Retz.) inflorescence. Brazilian Archives of Biology and Technology, 61(0). doi:10.1590/1678-43242018170802

9. Samanta, A. K., Konar, A., \& Chakraborti, S. (2011). Dyeing of Jute Fabric with Tesu Extract: Part 1- Effect of different Mordants and Dyeing Process Variables. Indian
Journal of Fibre and Textile Research, 36(1), 63-73.

10.Samanta, P. (2020). A review on application of natural dyes on textile fabrics and its revival strategy. Chemistry and Technology of Natural and Synthetic Dyes and Pigments. doi:10.5772/intechopen.90038

11.Savvidis, G., Karanikas, E., Nikolaidis, N., Eleftheriadis, I., and Tsatsaroni, E. (2014). Ink-jet printing of cotton with natural dyes. Coloration Technology, 130(3), 200-204. doi: $10.1111 /$ cote. 12087

12.Shabbir, M., Islam, S. U., Bukhari, M. N., Rather, L. J., Khan, M. A. and Mohammad, F. (2017). Application of Terminalia chebula natural dye on wool fiber-evaluation of color and fastness properties. Textiles and Clothing Sustainability, 2(1). doi:10.1186/s40689-016-0011-8

13.Shenai, V. A. 1997. Technology of Textile Processing $\left(2^{\text {nd }}\right.$ ed.). India, Sevaic Publications. p;159.

14.Tsering, J., Gogoi, B. J. and Tag, H. (2012). Ethnobotany and Phytochemical Analysis of PyrusPashia Leaves.International Journal of Pharmaceutical Sciences And Research, 3(8): 2721-2725.

15.Yusuf, M. (2018). Handbook of renewable materials for coloration and finishing. John Wiley \& Sons.pp33-34.

16.Zong, Y., Sun, P., Liu, J., Yue, X., Li, K. and Teng, Y. (2013).Genetic Diversity and Population Structure of Seedling Populations of Pyrus pashia. Plant Molecular Biology Reporter, 32(3):644-651. 